\title{
Construction of Diversified Academic Evaluation System of History Teaching Theory
}

Baoli Zhang

The History Department of College of Humanities in Qujing Normal University, Qujing 655011, Yunnan, China.

Abstract: The academic evaluation system, as an important content to help students better plan their future learning direction, in order to ensure the better development of students, teachers need to combine the actual teaching situation with the learning ability and speculative awareness of college students, and improve the evaluation system in a targeted manner in order to In the process of constructing a high-quality history classroom, the purpose of promoting the comprehensive development of students is achieved. This article starts with the obstacles faced by the academic evaluation of history teaching in colleges and universities, and finds a specific way to improve the evaluation system, hoping to provide reference for other teachers.

Keywords: Evaluation System; Higher Education; History Classroom; Diversification

History teaching theory integrates psychology and pedagogy into history teaching, so that students can better grasp the educational goals through knowledge learning, thereby ensuring the smooth progress of future employment. Therefore, as the subject of history education in colleges and universities, students need to focus on learning. In order to ensure the smooth progress of teaching, teachers need to integrate actual teaching conditions.

\section{Obstacles to the development of academic evaluation in history teaching theory classroom}

\subsection{Ignore individual differences among students}

The academic evaluation system established by many colleges and universities often puts the main purpose of the inspection on the students' learning achievements, so the test score becomes an important indicator to measure the students' learning level. In this evaluation mode, the school's test content is generally based on the scope of the exam outline. Not only does the student's learning content include comprehensive, but the difficulty of the paper meets the cognitive level of most students, in order to ensure the assessment The result is objective. However, in this evaluation system that ignores the individual differences of students, not only students will put their main academic achievements in memory knowledge, it is difficult to realize the importance of improving their professional qualities, practical abilities and learning abilities, taking student examination results as the assessment standard The evaluation goals also seriously reduce the enthusiasm of the students in their study, which in turn prevents them from achieving better overall development in the process of losing their self-development goals.

\subsection{Ignore students' professional skills}

History teaching theory, as a discipline that requires high research ability, teaching ability, and professional literacy of students, when teachers set up an academic evaluation system, they neglected the improvement of students' professional skills, which led to the evaluation focusing on the study of the effectiveness of student education theory. There is not enough attention to students' learning emotions, learning attitudes, learning needs and learning methods. Such an academic evaluation system not only makes it difficult to obtain the specific learning situation of students, but also reduces the enthusiasm of students 
to participate in classroom knowledge learning to a certain extent. Although the evaluation forms are diverse, in addition to assessing the student's test scores, there are also requirements for the writing of the teaching plan, the completion of the homework, and the attendance rate of the class. However, in the evaluation content that ignores the professional skills of the students, it is difficult to specifically reflect the students' The overall learning needs have led to serious obstacles to the smooth implementation of academic evaluation.

\section{The concrete ways of perfecting the academic evaluation system of the history teaching theory class in college}

\subsection{Formulate the evaluation content according to the actual situation}

The improvement of the academic evaluation system of history teaching theory requires teachers to be able to change the outdated evaluation viewpoints, through the actual learning situation of college students and professional personnel training standards, and to formulate evaluation content in a targeted manner, so as to ensure that students are in the evaluation system and ensure their learning The quality and professional teaching ability are rising rapidly. Teachers generally carry out teaching activities in two stages when teaching history pedagogy. They first teach students teaching principles and basic knowledge, and then focus on improving students' teaching ability, teaching experience and professional skills. Therefore, the content of academic evaluation should start from the functions of motivation, development, guidance, etc., so that students can get rid of the mode of mechanical learning knowledge, but through the setting of evaluation content such as historical teaching rules, teaching evaluation, teaching tasks and teaching modes, and provide students with multiple perspectives. Evaluation of comprehensive literacy.

\subsection{Formulate evaluation goals in combination with actual conditions}

Teaching ability is the core element for teachers to effectively carry out teaching work, and it is also an important condition to promote the overall development of students. Therefore, due to the particularity of the major itself, the history teaching theory classroom, as a student with high requirements on students' practical ability, teaching ability and professional literacy, the objective of the academic evaluation system cannot be blindly focused on examining the student's learning achievements, but requires the student's professional Teaching ability as a key evaluation target can cultivate high-quality history teacher talents that meet the needs of school development. At present, most schools will use the employment system to expand the teaching team. Therefore, when establishing a historical academic evaluation system, colleges and universities should take students' teaching ability, scientific research ability, practical ability and professional ability as the key evaluation goals in order to enable students to pass history teaching. On the participation of classroom learning activities, not only to ensure the rapid improvement of learning quality and professional skills, but also to formulate learning directions in a more clear evaluation goal, and then grow into high-quality teacher talents needed by the country.

\section{Conclusion}

In order to ensure that the academic evaluation system can promote the better development of students, teachers need to start with the learning needs of modern college students when carrying out the classroom work of history teaching theory, and combine the latest development prospects of the education industry to target the content of the evaluation system. Planning and improvement. Ensure the rapid correction of the learning direction, and can also fully mobilize students' enthusiasm for participating in classroom knowledge learning, so that they can continuously improve their own teaching ability and teaching experience in the process.

\section{References}

1. Sun WP. The application of Gagne's "nine-stage teaching" model in the course design of the "Secondary School History Teaching Method" in colleges and universities-teaching practice based on the "three-line construction" as an example. Journal of Liupanshui Normal University 2020; 32(01): 109-114.

2. Chen EL, Guo C. The evolutionary trajectory and evolutionary logic of the teaching management system of colleges and universities in the past 70 years in New China_-From the perspective of historical institutionalism. Journal of Sichuan Normal University (Social Science Edition) 2019; 46(05 ): 31-39.

3. Zhuang HH. Difficulties and countermeasures of undergraduate history education reform in western colleges and universities — Taking the teaching practice of cooperative learning in Guizhou University as an example. Education and Culture Forum 2019; 11(01): 99-103+139. 